\title{
QUALIDADE, FENÓIS E ENZIMAS OXIDATIVAS DE UVA 'ITÁLIA' SOB INFLUÊNCIA DO CÁLCIO, DURANTE A MATURAÇÃO'
}

\author{
MARIA AUXILIADORA COÊLHO DE LIMA², RICARDO ELESBÃO ALVES ${ }^{3}$, JOSTON SIMÃO DE ASSIS ${ }^{4}$, \\ HELOÍSA ALMEIDA CUNHA FILGUEIRAS ${ }^{5}$ e JOSÉ TARCISO ALVES COSTA
}

\begin{abstract}
RESUMO - Este trabalho foi realizado na Empresa Timbaúba Agrícola S.A., em Petrolina, PE, visando avaliar o efeito da aplicação, pré-colheita, de Ca, sobre a qualidade, teores de fenóis e atividade de enzimas oxidativas da uva (Vitis vinifera L.) 'Itália', durante a maturação. Utilizaram-se doses de Ca de $0,0,5,1,0$ e $1,5 \%$, na forma de cloreto de Ca diidratado, via imersão por 10 segundos, na fase de mudança de cor e início de amolecimento das bagas (57 dias após a formação dos frutos), em cachos marcados. Realizaram-se avaliações aos $28,43,57,72$ e 92 dias após a formação dos frutos. $\mathrm{O}$ delineamento experimental foi inteiramente casualizado, num fatorial $4 \times 5$, com quatro repetições. Analisaram-se as variáveis: sólidos solúveis totais (SST), acidez total titulável (ATT), relação SST/ATT, pH, fenóis totais e atividade das enzimas polifenoloxidase (PPO) e peroxidase (PDO). Com o aumento das doses de Ca, o teor de SST e a relação SST/ATT foram reduzidos. Entretanto, os valores de SST verificados atenderam à exigência de mercado. A atividade da PDO foi reduzida em 13,26\% pelo Ca na dose de $1,0 \%$ e aumentada em $27,15 \%$ pelo Ca $1,5 \%$, em comparação com a da testemunha. As demais variáveis não sofreram efeito do Ca exógeno.
\end{abstract}

Termos para indexação: Vitis vinifera, acidez, amadurecimento, peroxidase, polifenol oxidase, $\mathrm{pH}$.

\section{QUALITY, PHENOLS AND OXIDATIVE ENZYMES OF 'ITÁLIA' GRAPE UNDER CALCIUM INFLUENCE, DURING RIPENING}

\begin{abstract}
This work was conducted with the objective of evaluating the effect of preharvest Ca treatment on quality, phenols content and activity of oxidatives enzymes of 'Itália' grape (Vitis vinifera L.), during maturation, at Empresa Timbaúba Agrícola S.A, at Petrolina, Pernambuco State, Brazil. Application of $0,0.5,1.0$ and $1.5 \% \mathrm{Ca}$ was used, under the form of dihydrated calcium chloride, by immersion of the labelled bunches during 10 seconds, in the phase of color change and beginning of berry softening (57 days after fruit set). Evaluations were performed at 28, 43, 57, 72 and 92 days after fruit set. Experimental design was completely randomized in a factorial 4 x 5 , with four replications. The variables evaluated were: total soluble solids (TSS), total titrable acidity (TTA), TSS/TTA ratio, $\mathrm{pH}$, total phenols, polyphenoloxidase (PPO) and peroxidase (PDO) activities. TSS content and TSS/TTA ratio were reduced with the increment in calcium doses. However, the medium values of TSS attended the requirements of the market. PDO activity was $13.26 \%$ reduced by $\mathrm{Ca} 1.0 \%$ and it was $27.15 \%$ increased by $\mathrm{Ca} 1.5 \%$ compared to control. The other characteristics were not affected by exogen Ca.
\end{abstract}

Index terms: Vitis vinifera, acidity, ripening, peroxidases, polyphenol oxidase, $\mathrm{pH}$.

\footnotetext{
${ }^{1}$ Aceito para publicação em 14 de abril de 2000.

Extraído da Dissertação de Mestrado, apresentada pelo primeiro autor à Universidade Federal do Ceará (UFC), Fortaleza, CE.

${ }^{2}$ Eng. Agrôn., M.Sc., UFC, Caixa Postal 6012, CEP 60451-970 Fortaleza, CE.

${ }^{3}$ Eng. Agrôn., Dr., Embrapa-Centro Nacional de Pesquisa de Agroindústria Tropical (CNPAT), Caixa Postal 3761, CEP 60511-110 Fortaleza, CE. E-mail: elesbao@ cnpat.embrapa.br

${ }^{4}$ Eng. Agrôn., Dr., Embrapa-Centro de Pesquisa Agropecuária do Trópico Semi-Árido (CPATSA), Caixa Postal 23 CEP 56300-000 Petrolina, PE. E-mail: joston@ @ cpatsa.embrapa.br

${ }^{5}$ Bioquímica, Dr., Embrapa-CNPAT.

E-mail: heloisa@cnpat.embrapa.br

${ }^{6}$ Eng. Agrôn., Ph.D., Dep. de Fitotecnia, UFC.
}

\section{INTRODUÇÃO}

Um dos mais sérios problemas de conservação da uva 'Itália'é o escurecimento das bagas. No suco, este fenômeno é de origem essencialmente enzimática (Valero et al., 1989), sendo afetado pelos níveis de fenóis endógenos e das enzimas que os oxidam (Zapata et al., 1995).

$\mathrm{Na}$ presença de oxigênio atmosférico, a polifenoloxidase (PPO) catalisa a oxidação de certos compostos fenólicos naturais, formando pigmentos marrons, as melanoproteínas (Valero et al., 1989; 
Awad, 1993). Em uvas, o escurecimento oxidativo pode ocorrer também quando a PPO e fenóis entram em contato quando as bagas sofrem danos (Wissemann \& Lee, 1980; Awad, 1993).

O escurecimento do fruto de diferentes cultivares de uva tem sido registrado tanto na presença como na ausência de atividade da PPO (Romeyer et al., 1986), que é influenciada pelo estádio de desenvolvimento e pelas condições ambientais (Valero et al., 1989). Há, ainda, oxidação de fenóis resultante da atividade de peroxidases (PDO) ou mesmo sem participação de enzimas (Awad, 1993).

A evolução da atividade das enzimas PPO e PDO e do conteúdo de fenóis durante o desenvolvimento e o amadurecimento da uva 'Itália', especialmente nas condições da Região do Submédio São Francisco, ainda não foi estudada. E este conhecimento é fundamental para a viabilização de técnicas que reduzam as perdas decorrentes do escurecimento das bagas de uvas armazenadas.

A utilização de tratamento pré ou pós-colheita com $\mathrm{Ca}$ tem sido estudada por vários autores, visando prolongar a conservação de frutos e hortaliças. $\mathrm{O} \mathrm{Ca}$ altera vários processos relacionados ao amadurecimento (Ferguson, 1984), inclusive reduzindo a atividade de algumas enzimas (Siddiqui \& Bangerth, 1995a, 1995b). Sua utilização está relacionada, ain$\mathrm{da}$, ao controle do amolecimento e a outros aspectos da qualidade dos frutos (Poovaiah et al., 1988).

Este trabalho teve por objetivo avaliar o efeito da aplicação de Ca antes da colheita da uva 'Itália' sobre sua qualidade, teor de fenóis, e atividade de enzimas oxidativas, durante a maturação.

\section{MATERIAL E MÉTODOS}

O estudo foi realizado na Empresa Timbaúba Agrícola S.A., em Petrolina, PE, no período de 12 de outubro de 1997 a 16 de fevereiro de 1998. As plantas estavam no quinto ano de produção, em bom estado nutricional, definido por análise foliar, que indicou um teor de 2,10\% de Ca. O sistema de condução das plantas era em latada, num espaçamento de $3,0 \mathrm{~m} \times 2,5 \mathrm{~m}$, com irrigação por gotejamento, em Latossolo Amarelo distrófico de textura areno-argilosa. Os tratos culturais usados foram os mesmos recomendados e praticados na região.

Os tratamentos constaram de quatro doses de $\mathrm{Ca}$ e cinco fases de desenvolvimento, consideradas com referên- cia à data de formação dos frutos. A aplicação de $\mathrm{Ca}$, na forma de cloreto de Ca diidratado, nas doses de 0\%, 0,5\%, $1,0 \%$ e $1,5 \%$, foi feita por imersão dos cachos durante 10 segundos, na fase de início de amolecimento e mudança de cor das bagas (57 dias após a formação dos frutos). Os cachos haviam sido previamente marcados, durante a plena floração. Utilizou-se o espalhante adesivo alquilfenol-poliglicoleter $(0,3 \mathrm{~mL} / \mathrm{L})$.

As avaliações foram realizadas aos $28,43,57,72 \mathrm{e}$ 92 dias após a formação dos frutos. A terceira avaliação correspondeu, portanto, à data da realização dos tratamentos com Ca e a última, à colheita. Nas duas primeiras, foram coletados quatro cachos por repetição, uma vez que as aplicações ainda não haviam ocorrido. Nas avaliações seguintes, a amostragem correspondeu a quatro cachos por parcela.

O delineamento experimental usado foi inteiramente casualizado, num fatorial $4 \times 5$, constando de quatro repetições.

Foram avaliados: a) sólidos solúveis totais (SST) determinados por leitura em refratômetro (Association of Official Agricultural Chemists, 1992); b) acidez total titulável (ATT) determinada por titulometria com solução de $\mathrm{NaOH} 0,1 \mathrm{~N}$, expressando os valores em gramas de ácido tartárico por $100 \mathrm{~mL}$ de mosto (Instituto Adolfo Lutz, 1985); c) relação SST/ATT; d) pH determinado em potenciômetro, conforme normas estabelecidas por Instituto Adolfo Lutz (1985); e) fenóis totais doseados, após fracionamento, conforme Reicher et al. (1981), de modo que em cada fração, pesaram-se $15 \mathrm{~g}$ de suco em aproximadamente $50 \mathrm{~mL}$ de cada líquido extrator: metanol p.a., metanol:água $(1: 1, \mathrm{v} / \mathrm{v})$ e água, respectivamente, para extração de fenóis dímeros, oligoméricos e poliméricos. $\mathrm{Na}$ extração dos fenóis poliméricos, as amostras foram colocadas em banho-maria a $60^{\circ} \mathrm{C}$, por 15 minutos. No caso dos dímeros e oligoméricos, o material foi submetido a refluxo, por 15 minutos. Após a extração, as amostras foram agitadas por 15 minutos e filtradas. O filtrado foi evaporado até o volume aproximado de $5 \mathrm{~mL}$, e diluído em balão volumétrico de $50 \mathrm{~mL}$. Alíquotas de $1 \mathrm{~mL}$ foram utilizadas para o doseamento. As leituras foram feitas em espectrofotômetro a $720 \mathrm{~nm}$. Os resultados foram expressos em porcentagem de matéria fresca, correspondendo à soma dos fenóis dímeros, oligoméricos e poliméricos; f) polifenol oxidase extraída segundo método proposto por Wissemann \& Lee (1980), com modificações: homogeneizaram-se $20 \mathrm{~g}$ da amostra em $20 \mathrm{~mL}$ de uma solução $0,05 \mathrm{M}$ de tampão fosfato $\mathrm{pH} 7,0$, contendo $0,1 \mathrm{M}$ de $\mathrm{KCl}$ e $1,0 \%$ de polivinilpirrolidona. O homogenato foi filtrado a vácuo e centrifugado a $10.000 \mathrm{rpm}$ por 10 minutos. O sobrenadante obtido cons- 
tituiu a fonte enzímica. A atividade enzimática foi determinada incubando-se $0,3 \mathrm{~mL}$ do extrato, e $1,85 \mathrm{~mL}$ de tampão fosfato $0,1 \mathrm{M} \mathrm{pH}$ 6,0, contendo $0,1 \mathrm{M}$ de $\mathrm{KCl}$ e $0,1 \mathrm{M}$ de catecol, durante 30 minutos, a $30^{\circ} \mathrm{C}$. A reação foi interrompida pela adição de $0,8 \mathrm{~mL}$ de $\mathrm{HClO}_{4} 2 \mathrm{~N}$. Até a incubação, todo o procedimento foi realizado a $4{ }^{\circ} \mathrm{C}$. As leituras foram feitas a $395 \mathrm{~nm}$ e expressas em unidade de atividade enzimática (UAE)/min/g. Considerou-se uma UAE como a quantidade de atividade da enzima que produziu uma mudança de 0,001 na absorbância; g) peroxidase extraída segundo método de Wissemann \& Lee (1980), com as modificações usadas na extração da polifenoloxidase. A atividade foi medida conforme recomendação de Matsuno \& Uritani (1972), substituindo-se o substrato o-fenilenodiamina por guaiacol $1,0 \%$, adicionado diretamente à solução-tampão. As leituras foram feitas a $470 \mathrm{~nm}$ e expressas em UAE/min/g.

\section{RESULTADOS E DISCUSSÃO}

Houve significância estatística das fases de desenvolvimento em todas as variáveis estudadas (Tabela 1). As doses de Ca influenciaram significativamente o teor de SST, a relação SST/ATT, o pH e a atividade da PDO. A interação entre os dois fatores não foi significativa em nenhuma das variáveis.

A ATT teve um aumento inicial (de 3,60 para 4,35 g de ácido tartárico/100 $\mathrm{mL}$ de suco) até os 43 dias após a formação dos frutos, seguido por um decréscimo contínuo, principalmente depois dos 57 dias, e atingiu 0,92 g de ácido tartárico/100 mL de suco, na data da colheita (Fig. 1). O decréscimo na acidez da uva, segundo Ruffner et al. (1983), pode ser resultante: da diluição da concentração de ácidos por aumento no volume da baga; da ativação da degradação; da inibição da síntese, e da transformação em açúcares.

Não houve efeito significativo do Ca exógeno na ATT da uva. A mesma resposta foi obtida por Singh et al. (1985) com a aplicação de $\mathrm{CaCl}_{2}$ 0,5, 1,0 e 1,5\% na cultivar Himrod. No entanto, Cenci (1994) obteve, na colheita, ATT superior nas uvas Niágara Rosada tratadas com $\mathrm{CaCl}_{2}$. Segundo o autor, o Ca promoveu um atraso no amadurecimento das uvas.

Quanto ao pH, houve elevação ao longo do tempo, que se tornou mais evidente a partir dos 57 dias após a formação dos frutos (início do amadurecimento) e quando o aumento foi de 2,71 para 3,57, à colheita (Fig. 1). Um aumento no $\mathrm{pH}$ é esperado durante o desenvolvimento e amadurecimento da uva.

O teor de SST também aumentou durante o período estudado (Fig. 2), notadamente a partir dos 43 dias após a formação dos frutos, quando a taxa de aumento se acentuou, atingindo $15^{\circ}$ Brix. Este aumento também ocorreu no $\mathrm{pH}$ e coincidiu com a fase inicial de decréscimo na ATT (Fig. 1). Em virtude de tais transformações, pode-se considerar esta data como o início do amadurecimento do fruto.

TABELA 1. Resumo das análises de variância de sólidos solúveis totais (SST), acidez total titulável (ATT), potencial hidrogeniônico $(\mathrm{pH})$ e relação sólidos solúveis totais/acidez total titulável (RSA), fenóis totais (FT), atividade das enzimas polifenoloxidase (PPO) e peroxidase (PDO) de uva 'Itália' submetida a tratamento pré-colheita com cálcio, em diferentes fases de desenvolvimento e amadurecimento.

\begin{tabular}{|c|c|c|c|c|c|c|c|c|}
\hline \multirow[t]{2}{*}{ Fonte de variação } & \multirow{2}{*}{$\begin{array}{l}\text { Graus de } \\
\text { liberdade }\end{array}$} & \multicolumn{7}{|c|}{ Quadrados médios } \\
\hline & & SST & ATT & $\mathrm{pH}$ & RSA & FT & $\mathrm{PPO}$ & PDO \\
\hline Doses de cálcio & (3) & $\left(1,7971^{* *}\right)$ & $0,0330^{\mathrm{ns}}$ & $0,0023^{\text {ns }}$ & $\left(2,6073^{*}\right)$ & $0,0022^{\text {ns }}$ & $310,6540^{\mathrm{ns}}$ & $\left(448,6614^{*}\right)$ \\
\hline Regressão linear & 1 & $4,3890^{* *}$ & & & $5,5037^{* *}$ & & & $277,0061^{\text {ns }}$ \\
\hline Regressão quadrática & 1 & $0,9031^{\mathrm{ns}}$ & & & $0,7880^{\mathrm{ns}}$ & & & $393,7838^{\text {ns }}$ \\
\hline Regressão cúbica & 1 & $0,0992^{\mathrm{ns}}$ & & & $1,5302^{\mathrm{ns}}$ & & & $675,1942^{*}$ \\
\hline Fases & (4) & $\left(308,4014^{* *}\right)$ & $\left(31,6169^{* *}\right)$ & $\left(3,3831^{* *}\right)$ & $\left(649,1904^{* *}\right)$ & $\left(0,5706^{* *}\right)$ & $\left(3377,5148^{* *}\right)$ & $\left(9538,2940^{* *}\right)$ \\
\hline Regressão linear & 1 & $1196,4536^{* *}$ & $100,9206^{* *}$ & $12,4418^{* *}$ & $2118,2668^{* *}$ & $1,8130^{* * *}$ & $7828,1947^{* *}$ & $36875,3868^{* *^{\prime}}$ \\
\hline Regressão quadrática & 1 & $20,1863^{* *}$ & $11,5750^{* *}$ & $0,9882^{* *}$ & $471,7503^{* *}$ & $0,2024^{* *}$ & $3409,6164^{* *}$ & $626,2426^{*}$ \\
\hline Regressão cúbica & 1 & $13,9241^{* *}$ & $13,2712^{* *}$ & $0,1002^{* *}$ & $2,7256^{*}$ & $0,1426^{* *}$ & $2258,2838^{*}$ & $299,6578^{\text {ns }}$ \\
\hline Desvio de regressão & 1 & $3,0415^{* *}$ & $0,7009^{* *}$ & $0,0022^{\mathrm{ns}}$ & $4,0189^{*}$ & $0,1244^{* *}$ & $13,9642^{\mathrm{ns}}$ & $351,8890^{\text {ns }}$ \\
\hline Doses $\mathrm{x}$ fases & 12 & $0,3375^{\mathrm{ns}}$ & $0,0227^{\mathrm{ns}}$ & $0,0006^{\mathrm{ns}}$ & $1,0774^{\mathrm{ns}}$ & $0,0020^{\mathrm{ns}}$ & $752,2134^{\mathrm{ns}}$ & $172,4351^{\mathrm{ns}}$ \\
\hline Resíduo & 60 & 0,2864 & 0,0258 & 0,0010 & 0,6382 & 0,0088 & 448,3888 & 126,0107 \\
\hline $\mathrm{CV}(\%)$ & & 6,1080 & 5,6729 & 1,0836 & 14,6129 & 17,3481 & 16,4625 & 38,0084 \\
\hline
\end{tabular}

ns, * e ** Não-significativo e significativo a $5 \%$ e $1 \%$ de probabilidade, respectivamente. 


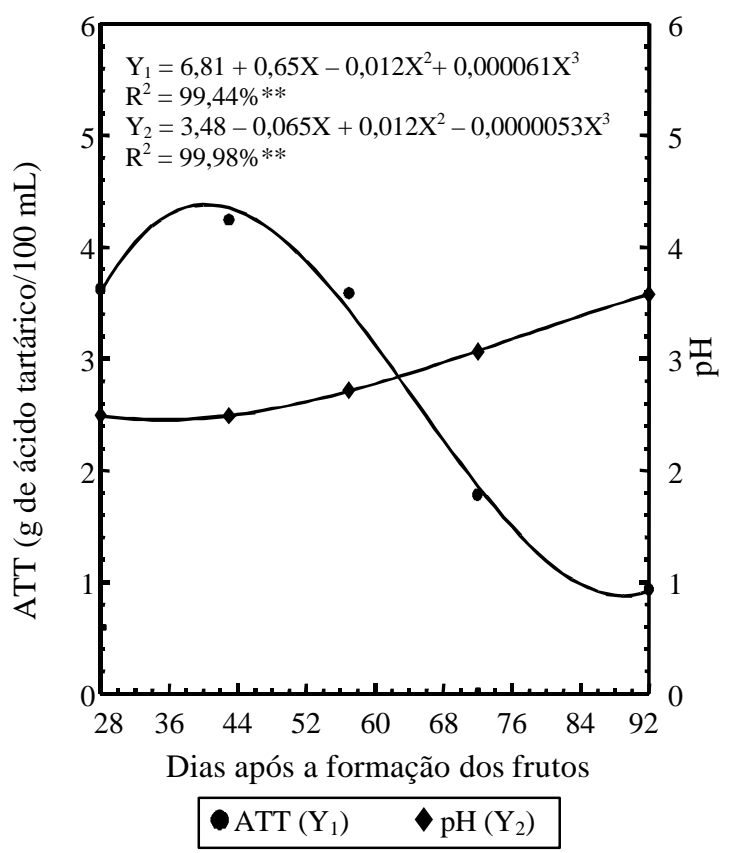

FIG. 1. Acidez total titulável (ATT) e pH de uva 'Itália', durante seu desenvolvimento e amadurecimento.

Em uvas maduras, um aumento em SST é geralmente relacionado à perda de água, sem mudanças no peso dos solutos por baga. E o decréscimo, é geralmente explicado pelo aumento em água por baga, embora possa estar associado também a uma perda de solutos decorrente da atividade respiratória, do transporte de solutos, da transpiração ou do transporte de água para outras partes da planta (Coombe, 1992).

O teor de SST também foi afetado pelas doses de $\mathrm{Ca}$ (Fig. 3). Houve um decréscimo linear de 2,20\%, $5,49 \%$ e $7,69 \%$, comparado à testemunha, com o aumento respectivo dos níveis de $\mathrm{Ca}$ de $0,5 \%$ até $1,5 \%$. Mas os teores de SST observados atingiram o valor mínimo de $15^{\circ}$ Brix, considerado, segundo Gayet (1993), como determinante do ponto de colheita da uva no Vale do São Francisco. A mesma resposta foi obtida por Singh et al. (1985) em uvas Himrod.

O Ca, segundo Bangerth et al. (1972), pode reduzir a taxa respiratória, por limitar a difusão dos substratos do vacúolo para o citoplasma. Conseqüen-

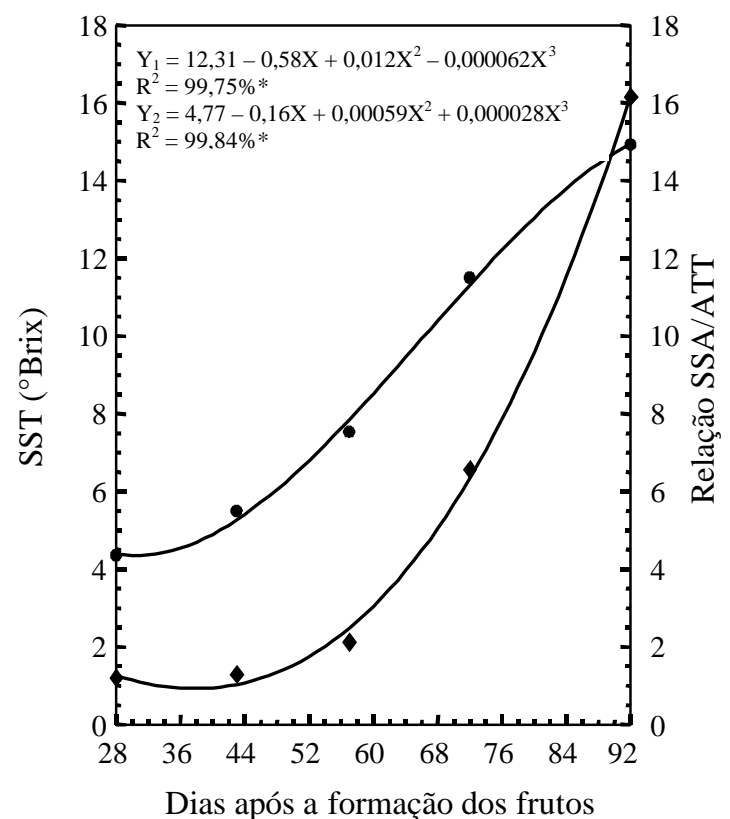

Dias após a formação dos frutos

- SST $\left(\mathrm{Y}_{1}\right) \diamond \mathrm{SST} / \mathrm{ATT}\left(\mathrm{Y}_{2}\right)$

FIG. 2. Teor de sólidos solúveis totais (SST) e relação acidez total titulável (SST/ATT) de uva 'Itália', durante seu desenvolvimento e amadurecimento.

temente, a concentração de frutose-2,6-bifosfato e o fluxo glicolítico são reduzidos (Brady, 1987).

A relação SST/ATT foi aumentando, ao longo do período estudado, desde valores de 1,27 até 16,19, principalmente nos 20 dias que antecederam a colheita (Fig. 2).

A relação SST/ATT diminuiu com os níveis de Ca aplicados (Fig. 3). Observaram-se reduções de $4,12 \%, 8,08 \%$ e $12,03 \%$ nos frutos que receberam Ca nas concentrações de $0,5 \%, 1,0 \%$ e $1,5 \%$, respectivamente, comparados à testemunha. Essa resposta foi consequiência do efeito das doses de $\mathrm{Ca}$ no teor de SST, já que a ATT não foi afetada por esse fator.

O teor de fenóis totais no fruto não sofreu efeito do Ca. Até o início do amadurecimento, o conteúdo de fenóis diminuiu, de $0,776 \%$ a $0,505 \%$ da matéria fresca (Fig. 4). Considerando-se os dados observados, verificou-se praticamente uma estabilização no teor de fenóis, a partir dos 57 dias. Os valores esti- 


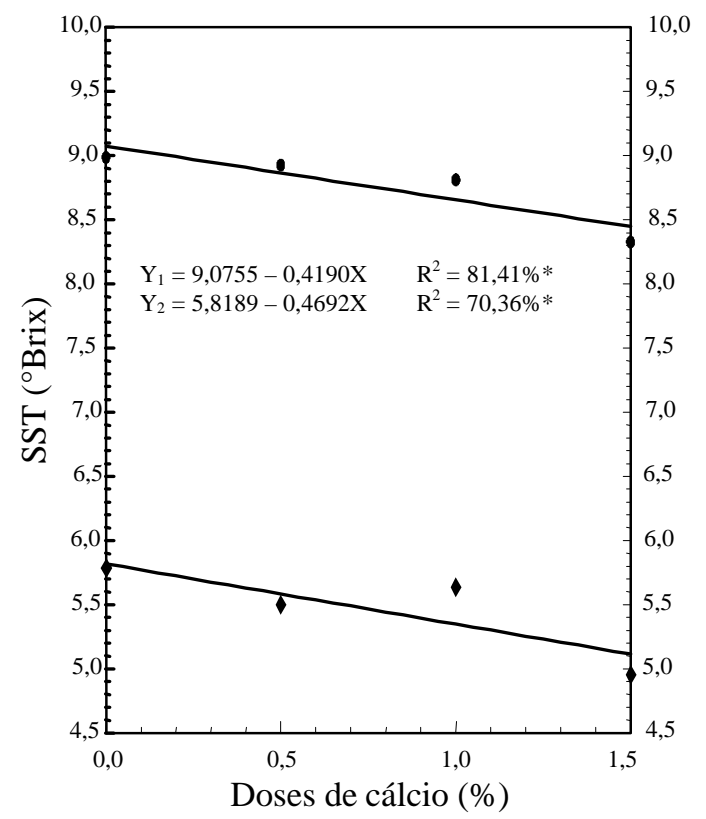

- $\operatorname{SST}\left(\mathrm{Y}_{1}\right) \diamond \operatorname{SST} / \mathrm{ATT}\left(\mathrm{Y}_{2}\right)$

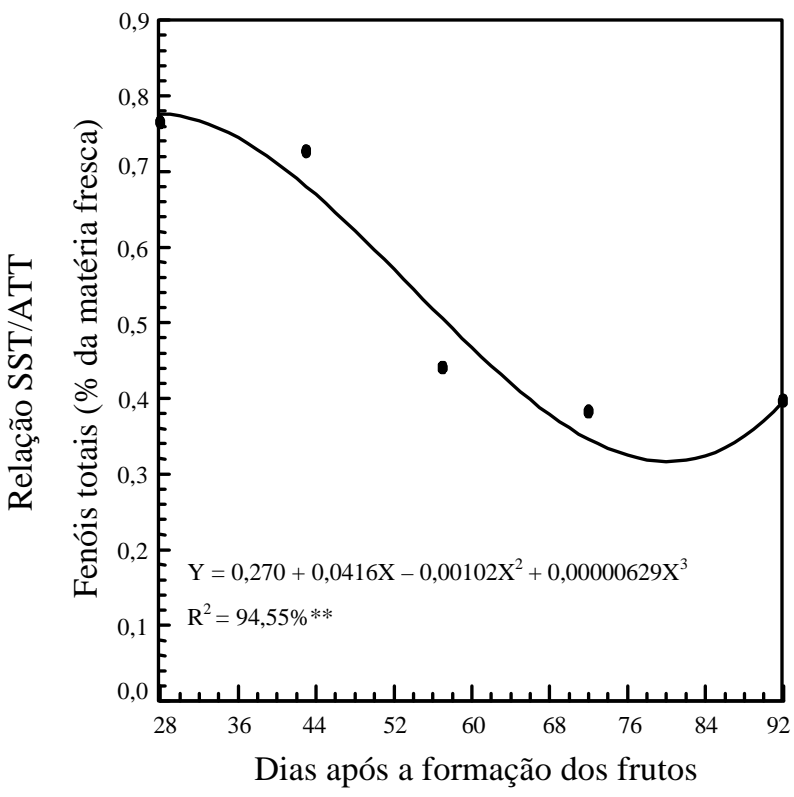

FIG. 4. Teor de fenóis totais de uva 'Itália', durante seu desenvolvimento e amadurecimento.

FIG. 3. Teor de sólidos solúveis totais (SST) e relação acidez total titulável (SST/ATT) de uva 'Itália' sob influência do cálcio pré-colheita.

mados pela equação de regressão, entretanto, demonstraram uma elevação próxima à colheita. Segundo Singleton et al. (1966), o decréscimo geral por unidade de peso com o amadurecimento da baga é resultante de um aumento relativamente maior no peso, que dilui e supera o grande acúmulo e provável síntese in situ de fenóis.

A atividade da PPO não sofreu efeito da aplicação de Ca. Ocorreu um decréscimo até os 43 dias após a formação dos frutos, em que se obteve a atividade mínima de 111,36 UAE/min/g e um aumento até a colheita, quando atingiu 148,26 UAE/min/g (Fig. 5). As alterações na atividade da PPO durante o desenvolvimento e amadurecimento da uva, conforme Valero et al. (1989), diferem entre as cultivares. Os valores e respostas observados, portanto, podem ser específicos da uva 'Itália'.

A atividade da PDO, por sua vez, aumentou quase linearmente dos 28 aos 57 dias após a formação dos frutos (Fig. 5), partindo de 3,63 e atingindo 25,07 UAE/min/g. A partir daí, o aumento tornou-se

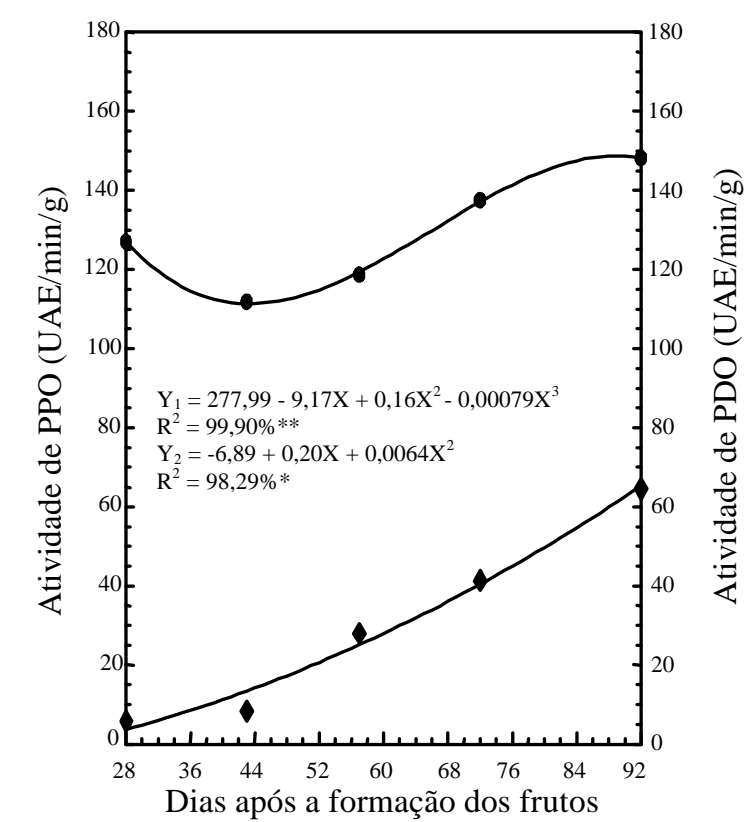

$\bullet \mathrm{PPO}\left(\mathrm{Y}_{1}\right) \triangleleft \mathrm{PDO}\left(\mathrm{Y}_{2}\right)$

FIG. 5. Atividade de polifenoloxidase (PPO) e peroxidase (PDO) de uva 'Itália', durante seu desenvolvimento e amadurecimento. 
ainda mais expressivo, atingindo incrementos sucessivos de $61,03 \%$, aos 72 dias após a formação dos frutos, e de $61,58 \%$, aos 92 dias.

Alterações tão evidentes na atividade da PDO sugerem que este também pode ser um bom indicador para caracterizar o estádio de amadurecimento da uva. Deve-se ressaltar que, segundo Burzo et al. (1988), a atividade da PDO é mais alta nos tecidos cujas células tiveram danos. Estímulos do meio, como estresse hídrico e danos mecânicos, podem desencadear a síntese de novo da enzima, elevando sua atividade (Civello et al., 1995).

$\mathrm{O}$ efeito do $\mathrm{Ca}$ sobre a atividade desta enzima (Fig. 6) revelou que a concentração de $1,0 \%$ contribuiu para reduzir em 13,26\% a atividade da PDO. A concentração de $1,5 \%$, em relação à do controle, entretanto, promoveu um incremento de $27,15 \%$ na atividade. Redução na atividade da PDO também foi obtida por Cenci (1994) em tratamentos pré-colheita com $\mathrm{CaCl}_{2} 1,0 \%$ na uva Niágara Rosada.

$\mathrm{O}$ tratamento com $\mathrm{Ca}$, portanto, reduziu a atividade da PDO até certo nível (1,0\%). A partir daí, o

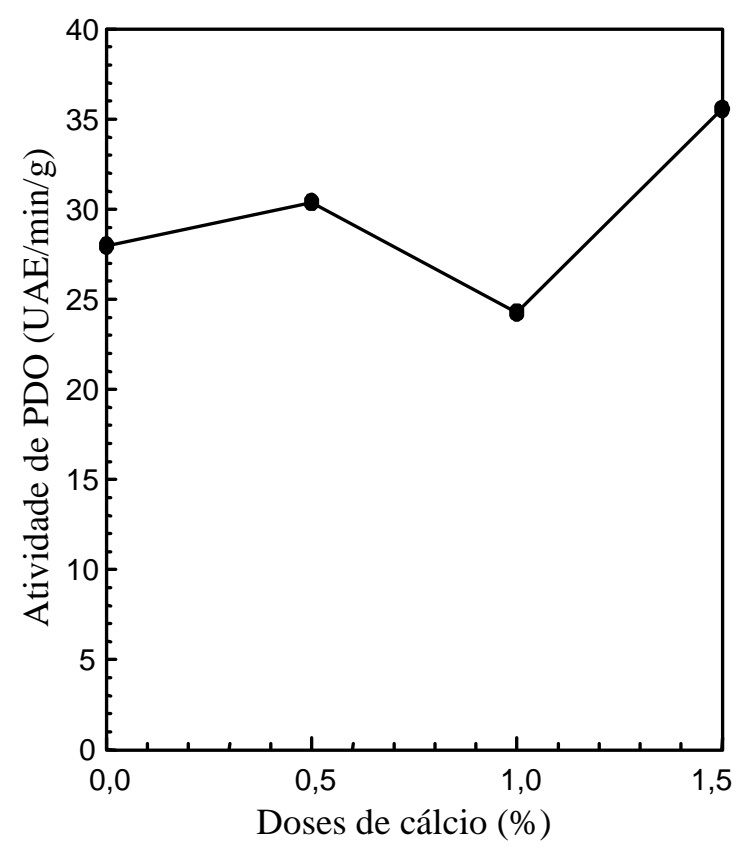

FIG. 6. Atividade de peroxidase (PDO) de uva 'Itália' sob influência de diferentes doses de cálcio aplicadas em pré-colheita. efeito foi inverso, indicando, possivelmente, tratarse de uma concentração ótima.

\section{CONCLUSÕES}

1. Os níveis de Ca aplicados não afetam a acidez total titulável (ATT), o pH, os teores de fenóis e a atividade da polifenoloxidase.

2. O aumento das doses de $\mathrm{Ca}$ de $0 \%$ para $1,5 \%$ reduz linearmente o teor de sólidos solúveis totais (SST) e a relação SST/ATT.

3. A aplicação de $\mathrm{Ca}$ reduz a atividade da peroxidase até o nível de $10 \%$, considerado como uma concentração ótima.

\section{REFERÊNCIAS}

ASSOCIATION OF OFFICIAL AGRICULTURAL CHEMISTS (Gaithersburg, Estados Unidos). Official methods of analysis of the Association of the Agricultural Chemists. 11.ed. Washington, 1992. $1115 \mathrm{p}$.

AWAD, M. Fisiologia pós-colheita de frutos. São Paulo : Nobel, 1993. 114p.

BANGERTH, F.; DILLEY, D.R.; DEWEY, D.H. Effect of postharvest calcium treatments on internal breakdown and respiration of apple fruits. American Society for Horticultural Science. Journal, Alexandria, v.97, n.5, p.679-682, 1972.

BRADY, C.J. Fruit ripening. Annual Review of Plant Physiology, Palo Alto, v.38, p.155-178, 1987.

BURZO, I.; FUGEL, S.; DOBREANU, M.; CRACIUN, C. Research concerning the browning during storage of Afuz-ali grapes. Lucrãri Stiintifice, Bucharest, v.19, p.55-61, 1988.

CENCI, S.A. Ácido naftalenoacético (ANA) e cloreto de cálcio na pré-colheita de uva Niagara Rosada (Vitis labrusca $\mathbf{L}$. X Vitis vinifera $\mathbf{L}$.): avaliação do potencial de conservação no armazenamento. Lavras : UFLA, 1994. 109p. Tese de Doutorado.

CIVELLO, P.M.; MARTÍNEZ, G.A.; CHAVES, A.R.; AÑÓN, M.C. Peroxidase from strawberry fruit (Fragaria ananassa Duch.): partial purification and determination of some properties. Journal of Agricultural and Food Chemistry, Washington, v.43, n.10, p.2596-2601, 1995. 
COOMBE, B.G. Research on development and ripening of the grape berry. American Journal of Enology and Viticulture, Davis, v.43, n.1, p.101-110, 1992.

FERGUSON, I.B. Calcium in plant senescence and fruit ripening. Plant, Cell and Environment, Oxford, v.7, p.477-489, 1984.

GAYET, J.P. Características das frutas de exportação. In: GORGATTI NETO, A.; GAYET, J.P.; BLEINROTH, E.W.; MATALLO, M.; GARCIA, E.; GARCIA, A.E.; ARDITO, E.F.G.; BORDIN, M. Uva para exportação: procedimentos de colheita e pós-colheita. Brasília : Embrapa-SPI/FRUPEX, 1993. p.9-11. (FRUPEX. Publicações Técnicas, 2).

INSTITUTO ADOLFO LUTZ (São Paulo, SP). Normas analíticas, métodos químicos e físicos para análise de alimentos. São Paulo, 1985. v.1.

MATSUNO, H.; URITANI, I. Physiological behavior of peroxidase isozymes in sweet potato root tissue injured by cutting or with black rot. Plant and Cell Physiology, Kyoto, v.13, p.1091-1101, 1972.

POOVAIAH, B.W; GLENN, G.M.; REDDY, A.S.N. Calcium and fruit softening: physiology and biochemistry. Horticultural Reviews, New York, v.10, p.107-152, 1988.

REICHER, F; SIERAKOWSKI, M.R.; CORREA, J.B.C. Determinação espectrofotométrica de taninos pelo reativo fosfotúngstico-fosfomolíbdico. Arquivos de Biologia e Tecnologia, Curitiba, v.24, n.4, p.407-411, 1981.

ROMEYER, F.M.; MACHEIX, J.J.; SAPIS, J.C. Changes and importance of oligomeric procyanidins during maturation of grape seeds. Phytochemistry, Cambridge, Grã Bretanha, v.25, n.1, p.219-221, 1986.

RUFFNER, H.P.; BREM, S.; MALIPIERO, U. The physiology of acid metabolism in grape berry ripening. Acta Horticulturae, Leuven, n.139, p.123-128, 1983.

SIDDIQUI, S.; BANGERTH, F. Differential effect of calcium and strontium on flesh firmness and properties of cell wall in apples. Journal of Horticultural Science, Ashford, v.70, n.6, p.949-953, 1995a.

SIDDIQUI, S.; BANGERTH, F. Effect of preharvest of calcium on flesh firmness and cell-wall composition of apples: influence of fruit size. Journal of Horticultural Science, Ashford, v.70, n.2, p.263-269, 1995b.

SINGH, K.; MANN, S.S.; BAJWA, M.S. Effect of auxins, sodium benzoate e calcium chloride on postharvest berry drop in Himrod grapes. Acta Horticultural, Addis Abeba, n.158, p.413-418, 1985.

SINGLETON, V.L.; DRAPER, D.E.; ROSSI JUNIOR, J.A. Paper chromatography of phenolic compounds from grapes, particulary seeds, and some varietyripeness relationships. American Journal of Enology and Viticulture, Davis, v.17, n.3, p.206-217, 1966.

VALERO, E.; SÁNCHEZ-FERRER, A.; VARÓN, R.; GARCÍA-CARMONA, F. Evolution of grape polyphenol oxidase activity and phenolic content during maturation and vinification. Vitis, Landau, v.28, n.2, p.85-95, 1989.

WISSEMANN, K.W.; LEE, C.Y. Polyphenoloxidase activity during grape maturation and wine production. American Journal of Enology and Viticulture, Davis, v.31, n.3, p.206-211, 1980.

ZAPATA, J.M.; CALDERÓN, A.A.; ROS BARCELÓ, A. Actual browning and peroxidase level are not correlated in red and white berries from grapevine (Vitis vinifera) cultivars. Fruit Varieties Journal, Fayetteville, v.49, n.2, p.82-84, 1995. 